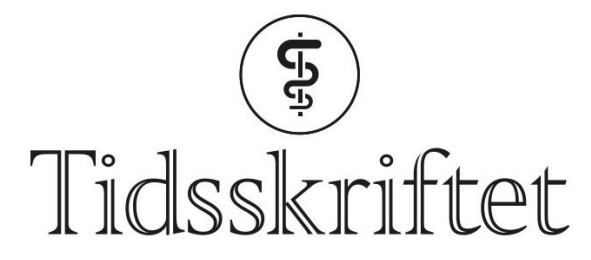

DEN NORSKE LEGEFORENING

\title{
Når medisinen går i ondskapens tjeneste
}

ESSAY

\section{PER NORTVEDT}

E-post: p.nortvedt@medisin.uio.no

Per Nortvedt er professor emeritus i medisinsk etikk, Senter for medisinsk etikk, Det medisinske fakultet, Universitetet i Oslo.

Forfatter har fylt ut ICMJE-skjemaet og oppgir ingen interessekonflikter.

Historien har lært oss at de første små skrittene mot båssetting og fremmedgjøring av mennesker kan lede opp mot en senere katastrofe. Faren for avhumanisering gjelder i høyeste grad leger.

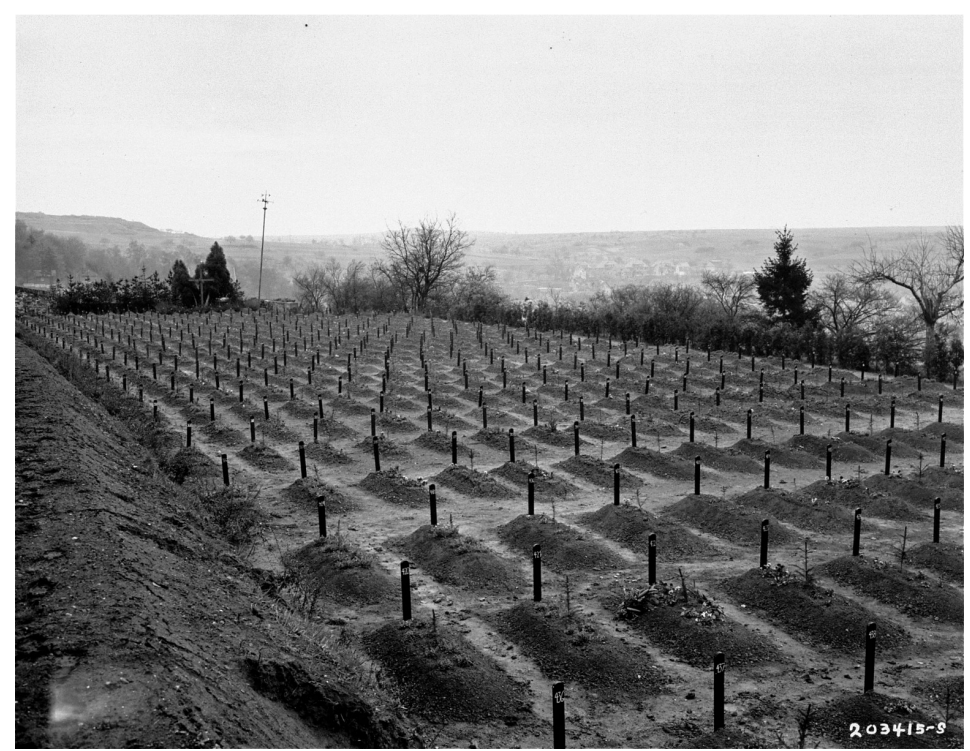

Gravgården ved Hadamar-instituttet, der ofrene etter nazistenes eutanasiprogram ble lagt $i$ massegraver. Hadamar-instituttet var et av seks sykehus og sanatorier i Tyskland og Østerrike der programmet ble utført. Foto: United States Holocaust Memorial Museum

«Hvis du er født i et land eller en tid der ingen kommer for å drepe din kone eller dine barn, og heller ikke noen kommer for å be deg drepe andres koner og barn, så takk din Gud og gå i fred. Men hold fast ved denne tanken: Du har kanskje vært heldigere enn meg, men du er ikke et bedre menneske» (1).

Dette sitatet fra Jonathan Littells bok om SS-oberstløytnant Aues udåder på Østfronten under den tyske invasjonen i 1941-42 har en uhyggelig undertone: Alle mennesker er disponert til å utføre onde handlinger hvis «de rette omstendigheter» (sosiale, politiske, ideologiske) er til stede. En slik påstand hviler på en antagelse om at menneskenaturen er 
ekstremt påvirkbar og at menneskelige handlinger er ytterst situasjonsbestemte, noe som er understøttet både av moderne moralpsykologisk forskning og holocaustforskning (2-4). Hvis det er slik at menneskenaturen er så påvirkbar, så bør mange trekk i vår samtid gjøre oss årvåkne overfor svikt i medfølelse med og brennemerking av folk og folkegrupper. Flyktningstrømmer som følge av fattigdom, kriger og klimakriser vil med stor sannsynlighet øke fremover. Samtidig ser vi også økende stigmatisering av folkegrupper samt sosial og politisk ustabilitet i mange deler av verden (5).

At utøvelsen av vold er mer avhengig av situasjonen enn personens karakteregenskaper, kan fra et profesjonsetisk perspektiv virke som en tvilsom påstand. Vi liker å tenke at personlig overbevisning, utdanning og robuste, stabile karaktertrekk utgjør et godt vern mot moralsk korrumpering. Særlig tenker vi at vår personlighet danner skranker, særlig mot å utøve grov vold og drap på mennesker uansett kjønn og alder. Det synes imidlertid ikke å være tilfellet.

Betingelsene for at vanlige mennesker kan begå drap og etnisk rensing, er sammensatte, men likevel høyst nærliggende og reelle. Vi vet i dag at «vanlige» tyske familiefedre og politisoldater deltok i de verste massemyrderier i historien på Østfronten under den tyske invasjonen av Sovjetunionen fra juni 1941. Vi vet at mange av disse personene ikke engang var nazister og at de ikke ble tvunget til å gjøre sine ugjerninger, ei heller ble de få som vegret seg mot å drepe, straffet på noen måte $(3,5,6)$. Det samme gjaldt de legene og sykepleierne som ikke ville utføre drap på uskyldige pasienter som en del av nazistenes eutanasiprogram i 1939-41, et program for drap på syke og psykisk utviklingshemmede som ble videreført i det skjulte til krigens slutt (7). Og ikke minst vitner i nyere tid folkemordene og etnisk rensing i Bosnia og Rwanda at «vanlige mennesker» kan bli mordere, endog massmordere $(3,8)$.

\section{Teorier om ondskap}

Teorier om kollektiv ondskap, definert som ondskap på vegne av sosiale/etniske grupper med den hensikt og mot personers vilje å påføre ubotelig skade og lidelse, har flere forklaringsmodeller (3). Mest kjent er teoriene til den polske sosiologen Zygmunt Bauman om distansering og byråkratisering som grunnlag for kollektive overgrep. Essensen i Baumans syn er at nærhet skaper moralske bånd og impulser som må overvinnes for at grupperelatert vold i stor skala skal være mulig. Dette skal ha vært grunnen til at nazistene etter hvert gikk over fra ansikt til ansikt-drap til systematisk utrydning ved gass kombinert med fysisk og ideologisk avhumanisering av ofrene. Distansering ble særlig nødvendig da man etter hvert skulle utføre massedrap også på kvinner og barn i alle aldre $(3,5)$.

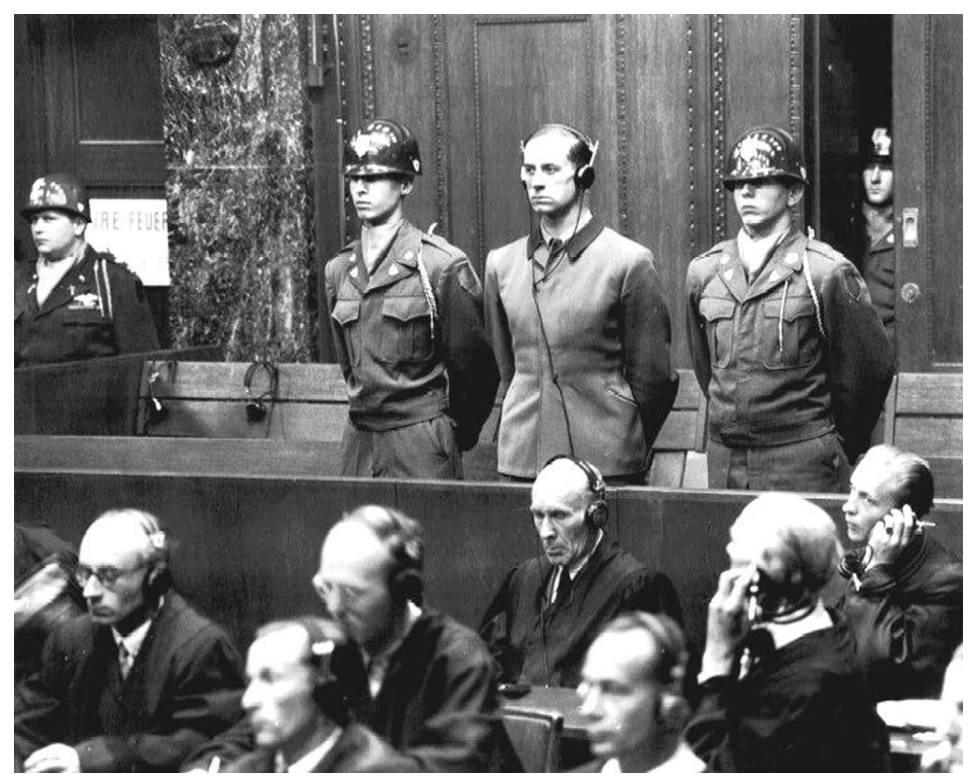

Karl Brandt, Adolf Hitlers da 43 år gamle livlege, ble dømt til døden ved hengning $i$

Nürnbergprosessen. 
Haken ved Baumans syn, som særlig historikere i nyere tid har vist $(3,4,9)$, er at det i liten grad var moralske anfektelser som fikk unge tyske soldater til å reagere på volden de utførte. Det var voldens sterke sanseinntrykk (syn og lyd) som ga psykiske traumer hos gjerningsmennene, mens evnen til empati med ofrene, hvis den var der i utgangspunktet, ble minimalisert etter ganske kort tid. Lifton beskriver i sin berømte studie hvordan legene i Auschwitz etter 1-2 uker med såkalt "ramp duty», der de skulle lede seleksjonsprosessene når jødetransportene kom inn, etter hvert hadde få skrupler ved det de gjorde (10). Det var altså ikke medfølelse med ofrene som tvang nazistene, med hjelp fra tyske leger, til å revolusjonere henrettelsemetodene fra skyting til ihjelgassing.

Teoriene, særlig til den tyske sosialpsykologen Harald Welzer (4), er at volden i stor grad ble en referanseramme som personene godtok og tilpasset seg. Krigen skaper et handlingsrom der det som før var ansett som helt uhørt og umulig, blir mulig. Volden blir et sosialt lim for den utøvende gruppen. Drap er ødeleggende, men bare for ofrene, ikke for drapsmennene, hevder Welzer: «Behovspotensialet til helt normale mennesker, som kan være harmløst eller godtatt bare i bestemte samfunnsnisjer, eller omgitt av trusler om sanksjoner, kan utfolde seg fullstendig annerledes under nye omstendigheter. Og det er hele hemmeligheten bak nasjonalsosialismens umenneskelige utfoldelse: Åpningen av sosiale handlingsrom der det som tidligere var forbudt, plutselig blir tillatt» (4, s. 37).

Fra den politiske etikkens perspektiv er ikke dette optimistiske toner. Men det er det heller ikke for den medisinske etikken og profesjonsetikken. Kanskje særlig er det to ting som en profesjonsetikk må være bevisst. Det ene er at etiske prinsipper i liten grad bidrar til å forhindre overgrep, selv om personen i utgangspunktet er en skolert og etisk bevisst person. Prinsipper kan omtolkes og tilpasses den aktuelle situasjonen, slik leger har brukt hippokratiske prinsipper om velgjørenhet til å forsvare drap på uskyldige: Man drepte for å spare pasientene for det man mente var et uverdig liv i lidelse $(7,11,12)$. I tillegg er empati og evne til medfølelse med andre mennesker som utviklingspsykologisk og evolusjonsbiologisk produkt i liten grad i stand til å hindre at mennesker begår overgrep mot andre (3). Vanens makt er stor, også når det gjelder umoral. Medisinen er intet unntak.

\section{Når profesjonsetikken forvitrer}

Historien har tvert imot lært oss at noen av de som vi tillitsfullt betror vår skjebne og våre liv til, kan svikte når det gjelder som mest. Leger spilte en sentral rolle i nazistenes folkemord og ikke minst i drapet på psykiatriske pasienter, funksjonshemmede og psykisk utviklingshemmede. 70 ooo ble drept i det offisielle eutanasiprogrammet ( $\mathrm{T}_{4}$-programmet) som ble avsluttet i 1941, men drapene på pasienter fortsatte under ledelse av Hitlers sjefslege Karl Brandt i det skjulte frem til krigens slutt. Til sammen ble nærmere 250 ooo mennesker $\operatorname{drept}(7)$.

Erfaringene legene gjorde i eutanasiprogrammet, blant annet med gassing av pasienter $\mathrm{i}$ lastebiler, ble senere brukt til å utvikle gasskamre til bruk i tilintetgjørelsesleirene. I tillegg tok tyske leger livet av 2500 menn, kvinner og barn i medisinske eksperimenter (7). Lik fra døde og henrettede samt biologisk materiale fra ofrene ble brukt i undervisning ved tyske universiteter i medisinutdanning helt opp til 199o-årene (10,12). Det tok nesten 70 år før den tyske legeforeningen i 2012 offentlig beklaget tyske legers deltagelse i Holocaust. Karl Brandt holdt helt til sin henrettelse i Nürnberg fast ved at drapet på syke mennesker var en barmhjertighetsgjerning og dermed en god moralsk handling. Han omdefinerte det klassiske legeetiske prinsippet om å handle godt til at drap var i det godes tjeneste (13). De fleste av de som ble dømt for drap og folkemord i 1946-47 slapp ut etter noen få år og fortsatte senere i sine yrker som virksomme leger og sykepleiere $(10,11)$.

\section{Hvordan kunne det skje?}

Det er mange forsøk på å forklare medisinens forfall i denne perioden. Man kan ikke se bort fra den rollen som rasehygienen spilte i mellomkrigstiden. Dette gjaldt ikke bare i Tyskland, 
både amerikansk og norsk medisin hadde betydelige innslag av rasehygienisk praksis og tenkning. Nazistenes lovgivning om rasehygiene fra 1935 var betydelig inspirert av amerikansk steriliseringslovgivning fra 1907. Norge innførte en steriliseringslov i 1933 basert på tyskinspirerte rasehygieniske prinsipper. Forskjellen var at den norske loven ga enda mindre rettsvern enn den tyske, ettersom den tillot tvangssterilisering uten dom (14). Den norske steriliseringsloven ble ikke revidert før i 1971.

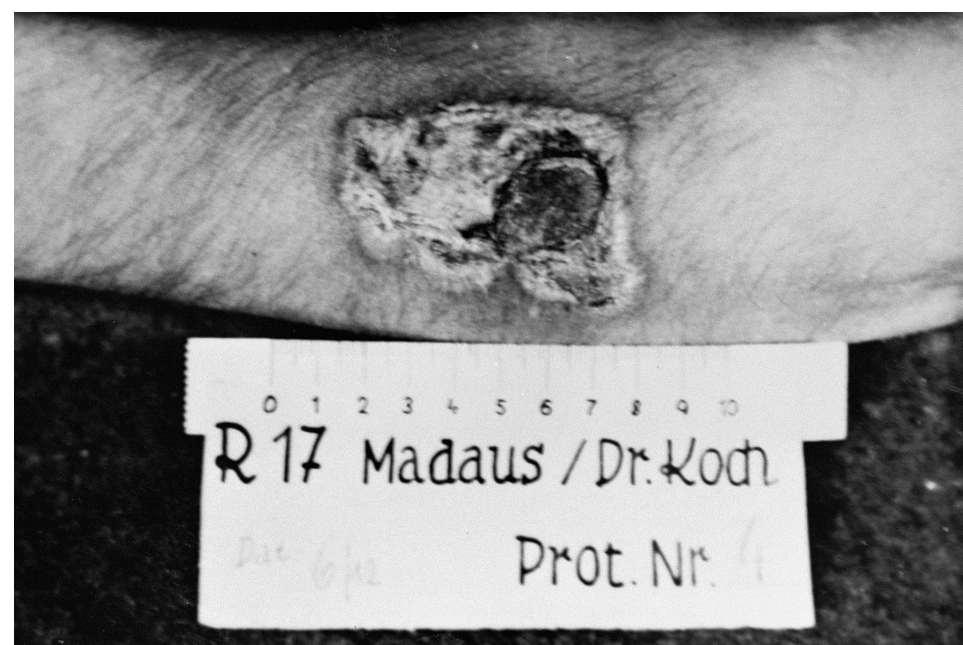

Resultatet av et medisinsk eksperiment med fosfor utført av leger i Ravensbrück konsentrasjonsleir. Foto: United States Holocaust Memorial Museum

I Tyskland var en viktig årsak til legeetikkens korrumpering den mulighet for makt og de karrieremuligheter både antisemittismen og rasehygienen skapte for tyske leger da jødiske leger mistet sine stillinger fra og med nazistenes maktovertagelse i 1933. Forfølgelsen og oppsigelsen av den jødiske delen av legestanden medførte at «arisk rene» og ofte langt mindre dyktige leger fikk karrieremuligheter og stillinger ved de tyske universitetene. Legene hadde i tillegg en helt spesiell plass i Hitlers prosjekt som «biologiske soldater». De skulle fremme den "ariske revolusjonen" gjennom tvangssterilisering, utestengning og direkte drap på uskyldige mennesker $(9,10)$. Likevel kan det synes som om en viktig årsak til at medisinen så lett kunne bli et bytte for nazismens ideologi og propaganda, også er å finne i den kimen til umoral som ligger i legerollen og i det rådende biomedisinske kunnskapssynet.

\section{«Leger er eksperter på dehumanisering»}

At det er trekk ved legerollen og medisinens kunnskapssyn som kan fremme umoral, er blant påstandene holocaustforskeren Michael Grodin fremsetter i boken Medicine after the Holocaust (15). Det betyr ikke at leger er spesielt ondere eller mindre gode enn andre, men at legeyrket forholder seg til død, blod, sykdom og menneskelig sårbarhet på en helt spesiell måte. Det er ingen yrkesgruppe som har så stor makt og tillatelse til å intervenere i andre menneskers liv som legene. 


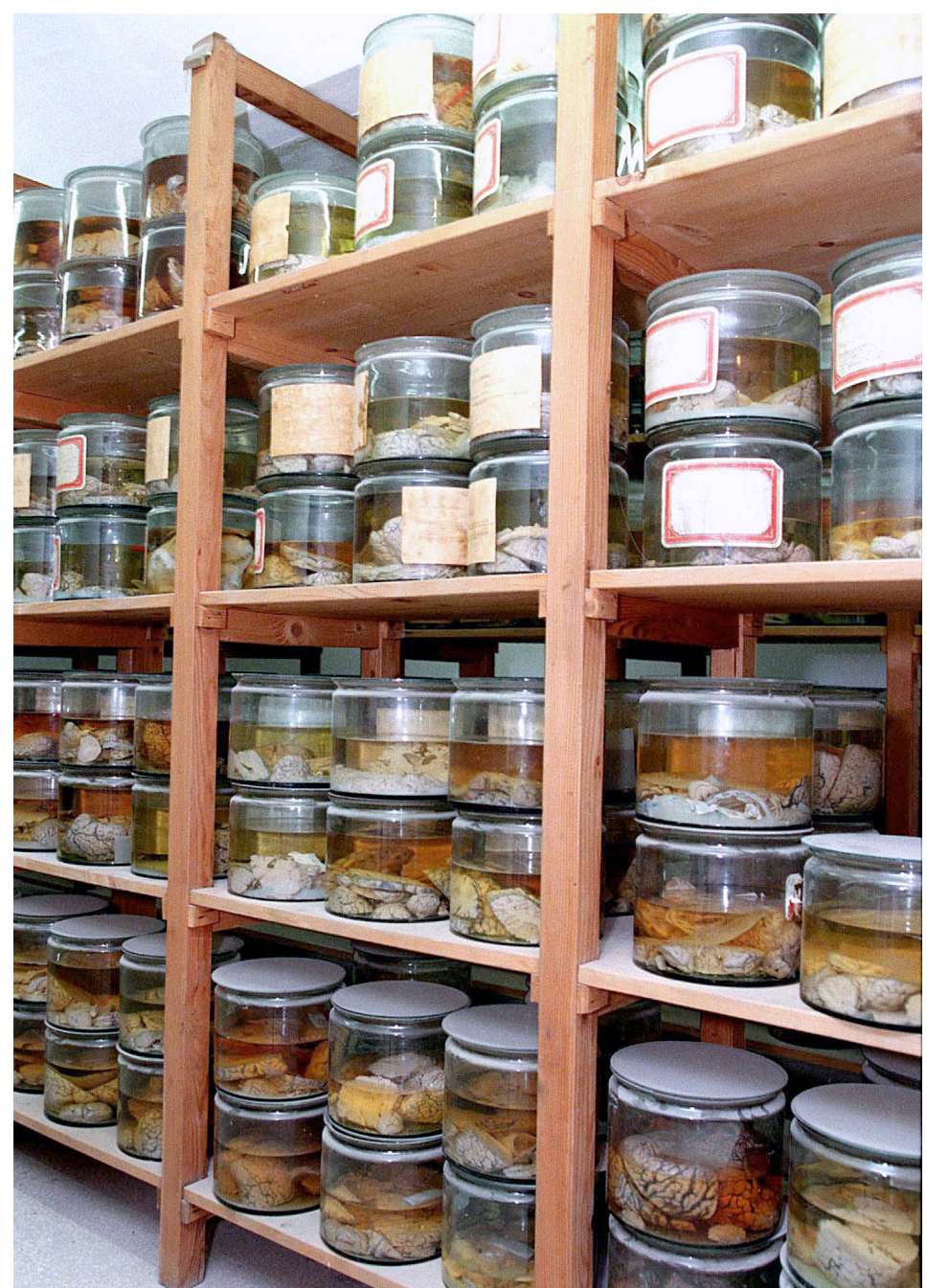

Noen av hundrevis av bevarte hjerner fra barn med fysiske eller psykiske funksjonsnedsettelser som ble drept i nazistenes eutanasiprogram. Foto: Ronald Zak / NTB Scanpix

Den biomedisinske kunnskapen omfatter biologi, kropp, vev og anatomiske strukturer, og i mindre grad kunnskap om det syke mennesket som et følende, tenkende og erfarende subjekt. For å behandle må en lege ha et betydelig fokus på sykdommens årsaker og kanskje i mindre grad på den sykes opplevelse som pasient. En lege helbreder mange ganger gjennom å skade og gjennomfører undersøkelser som er invasive og som kan være smertefulle. Det stikkes og skjæres, hud og slimhinner blottlegges, det kuttes i hudnerver og skrus i ben. Alt dette for å hjelpe. Samtidig må legen trøste den sørgende, informere den som er engstelig og bringe de mest alvorlige budskap til pasient og familie med empati og omtanke.

Men i dette «legende» arbeidet må en lege også kontrollere egne følelser og innta en emosjonell avstand til andres smerte og lidelse. Dette synliggjør en dobbelthet i medisinen som legen må forholde seg til: både å påføre og lindre lidelse. I dette skjæringspunktet mellom medmenneskelig nærhet og distanse til lidelse er det av uvurderlig betydning å bevare følsomhet for andre. Her ligger det alltid en fare for å utvikle ufølsomhet. Derfor kunne også en overlevende fra Auschwitz si: «Legen, hvis han ikke lever i en situasjon der grensene er veldig tydelige, er en farlig person» (7, s. 430). Vi vet også at propaganda og gruppepress på kort tid kan bryte ned evnen til medfølelse.

Studier av empatiutvikling i løpet av medisinstudiet viser at studentene midtveis i studiet kan se på medfølelse og empati som en trussel mot profesjonalitet (16). Det er også dokumentert i internasjonal forskning at medisinstudentene strever med en legerolle der både medfølelse og profesjonell distanse skal balanseres (17). 


\section{Utfordringer i fremtiden}

«Skjebnen til de europeiske jødene var beseglet fra det øyeblikket en funksjonær i 1933 gjennom en forordning slo fast hvem som var 'arisk' og hvem som ikke var det» (5). Disse ordene fra den berømte holocaustforskeren Raul Hilberg rammer inn kjernen i det nasjonalsosialistiske prosjektet og dermed et av de største massemyrderier verden har sett. Med den tyske sosialpsykologen Harald Welzers ord: «En viktig forutsetning (for myrderiene under Holocaust, min anm.) var tesen om at mennesker er radikalt og uforsonlig ulike og at fredelig sameksistens uavhengig av kultur og etnisk opprinnelse er en umulighet» (ibid). Er det noen som kjenner igjen denne tankegangen? Å glemme det menneskelige subjektet i medisinen kan under gitte betingelser få katastrofale følger. Vi trenger derfor en profesjonsetikk i medisinen som vektlegger kritisk refleksjon og analyse, men også kultivering av moralsk sensitivitet og omsorgsevne.

Dersom faren for avhumanisering gjelder leger - en gruppe som innehar stor tillit og status blant befolkningen - må vel også denne faren kunne gjelde oss alle? Flyktningstrømmene vi ser i dag er antagelig bare begynnelsen på enda større folkevandringer som vil komme med bakgrunn i krig, fattigdom og miljøødeleggelser. Dette vil virkelig sette vår toleranse og respekt for andre mennesker på prøve. Welzer sier igjen: «For at mennesker skal bestemme seg for å drepe andre mennesker, holder det at de føler seg eksistensielt truet, og/eller legitimt oppfordret til det og/eller at de ser en politisk, kulturell eller religiøs mening i det». Historien har lært oss at de små første skritt mot å fremmedgjøre og sette mennesker i bås kan lede opp mot en senere katastrofe. Vi trenger derfor en politisk offentlighet som er vidsynt og inkluderende, ikke en som er snevert nasjonalistisk og selvsentrert, konfronterende og ekskluderende.

\section{LITTERATUR:}

1. Littel J. De velvillige. Oslo: Aschehoug, 2006.

2. Zimbardo P. The Lucifer Effect - Understanding How Good People Turn Evil. New York, NY: Random House, 2007.

3. Vetlesen AJ. Evil and Human Agency: Understanding Collective Evildoing. Cambridge: Cambridge University Press, 2005.

4. Welzer H. Täter: Wie aus ganz normalen Mänschen Massenmörder warden. Frankfurt: Frankfurt/M.Fischer, 2005.

5. Welzer H. Climate Wars. Why People Will Be Killed in the $21^{\text {st }}$ Century. Cambridge: Polity, 2012.

6. Goldhagen DJ. Hitler's Willing Executioners: Ordinary Germans and the Holocaust. Cambridge, MA: Harvard University Press, 1997.

7. Burleigh M. Death and Deliverance: 'Euthanasia' in Germany 1900-1945. Cambridge: Cambridge University Press, 1994.

8. Hagtvet B, Brandal N, Thorsen DE et al. Folkemordenes svarte bok. 2. utg. Oslo: Universitetsforlaget, 2014.

9. Browning CR. Ordinary Men: Reserve Police Battalion 101 and the Final Solution in Poland. New York, NY: Harper Collins, 1992.

10. Lifton RJ. The Nazi Doctors: Medical Killing and the Psychology of Genocide. New York, NY: Basic Books, 1986.

11. Friedlander H. The Origins of Nazi Genocide: From Euthanasia to the Final Solution. Chapel Hill, NC: University of North Carolina Press, 1995.

12. Proctor RN. Racial Hygiene. Medicine Under the Nazis. Cambridge, MA: Harvard University Press, 1988.

13. Schmidt U. Karl Brandt - The Nazi Doctor. London: Hambledon Continuum Books, 2007. 
14. Bastrup ORE, Sivertsen AG. En landevei mot undergangen: Utryddelsen av taterkulturen i Norge. Oslo: Universitetsforlaget, 1996.

15. Rubenfeld S. red. Medicine after the Holocaust. From the Master Race to the Human Genome and Beyond. New York, NY: Palgrave Macmillan, 2010.

16. Eikeland HL, Ørnes K, Finset A et al. The physician's role and empathy - a qualitative study of third year medical students. BMC Med Educ 2014; 14:165. [PubMed][CrossRef]

17. Neumann M, Edelhäuser F, Tauschel D et al. Empathy decline and its reasons: a systematic review of studies with medical students and residents. Acad Med 2011; 86: 996-1009. [PubMed][CrossRef]

Publisert: 25. februar 2019. Tidsskr Nor Legeforen. DOI: 10.4045/tidsskr.18.0685

(C) Tidsskrift for Den norske legeforening 2020. Lastet ned fra tidsskriftet.no 